\title{
ПЕРЕДАЧА ЭТНОГРАФИЧЕСКИХ ЗНАНИЙ СРЕДСТВАМИ ШКОЛЬНОГО ГЕОГРАФИЧЕСКОГО ОБРАЗОВАНИЯ
}

\section{ETHNOGRAPHIC INFORMATION TRANSFER BY MEANS OF GEOGRAPHIC SCHOOL EDUCATION}

\section{Petrukhina}

Summary: The paper analyzes the potential and role of geography lessons in the process of students' obtaining the knowledge about material and spiritual culture of their and other peoples and ethnic groups. This knowledge serves as a basis for ethnic identity and intercultural competence. The analysis of modern basic educational curricula allowed the author to pinpoint the subjects that provide students with ethnographic information. The subject of geography is the main one among them as it provides the largest amount of data on ethnic composition of different countries and regions, their cultural specificity and its connection to the natural environment of the settlement areas. The modern lesson types and their contents as well as pedagogical methods allow for better absorption of the ethnographic information by the students and promote the motivation to learn more.

Keywords: secondary school education, pedagogical methods, geography at school, intercultural competence, ethnocultural content, ethnographic information.

\author{
Петрухина Дарья Валерьевна \\ аспирант, Институт этнологии и антропологии \\ им. Н.Н. Миклухо-Маклая РАН (2. Москва) \\ darkamercante@gmail.com
}

Аннотация: Статья посвящена выявлению потенциала уроков географии в процессе накопления учащимися знаний о материальной и духовной культуре своего и других народов, являющихся основой для формирования этнического самосознания и этнокультурной компетентности. Анализ современных примерных основных образовательных программ позволил выделить предметы, при изучении которых учащиеся получают различные этнографически знания. География занимает среди них ведущее место, поскольку призвана передавать наибольший объем знаний об этническом составе населения стран и регионов, особенностях культуры народов и их связи сприродой территории расселения. Рассмотренные в статье современные типы уроков, содержание учебного материала и методический корпус способствуют лучшему усвоению учащимися этнографических знаний, поддержанию интереса и мотивации к их дальнейшему получению.

Ключевые слова: основное общее образование, методы преподавания, географическое образование, этнокультурная компетентность, этнокультурное содержание, этнографические знания.
И здавна сохранение любого знания обеспечивалось его передачей из поколения в поколение. Механизмы и средства этого процесса могут быть разнообразны: от устных преданий, мифов и легенд, передающихся в песнях и других фольклорных формах, до многотомных письменных источников и современных электронных носителей, но объектом такой передачи в большинстве случаев выступают дети и подростки.

Особое место в системе передаваемых знаний занимает информация о собственном народе и окружающих его соседях, с которыми имеются исторически сложившиеся взаимоотношения. С ее помощью формируется этническая идентичность (самосознание) личности, происходит социализация внутри своей этнической общности, выстраивается картина мира, характерная для данной конкретной культуры, конструируются образы исторических «друзей» и «врагов». Такой комплекс знаний о происхождении (этногенезе) и истории народов, этнической культуре (языке, обычаях, традициях, способах жизнеобеспечения, материальной и духовной культуре, социальных институтах и т.д.) своего и других народов можно обобщенно назвать этнографическими знаниями. Традиционно такие знания передаются мо- лодому поколению в процессе обучения и воспитания (образования). Для ребенка главную роль в трансляции ценностей культуры собственного народа играет семья, которая также может влиять и на появление у него стереотипов о представителях других этносов. Однако большую часть фактической информации о культуре других народов он получает во время обучения в школе и далее, в течение всей жизни.

Этнографические знания играют важную роль в формировании этнокультурной компетентности человека, являясь ее фундаментальной основой. Т.В. Поштарева называет совокупность представлений ребенка об антропологическом типе, хозяйстве и традиционных ремеслах людей, географии и природных условиях их расселения, обычаях и традициях народов, первым критерием сформированности этнокультурной компетентности [6, с. 101]. Ее важной составляющей также является осознание собственной этнической идентичности и знание (соблюдение) норм этикета, принятых в культуре своего народа [6, с. 103].

В современной России основные знания, умения и навыки формируются у детей в школьном возрасте в 
процессе получения общего образования, основу которого составляет классно-урочная система обучения.

Классно-урочная система - организация процесса обучения, разработанная Я.А. Коменским, при которой для проведения учебных занятий учащиеся группируются по возрасту в классы, а основной формой обучения является урок [1, с. 93-94]. Каждый урок представляет собой занятие по определенному предмету, содержание которого регламентировано Федеральным государственным образовательным стандартом и Примерной основной образовательной программой, где определены требуемые результаты освоения каждого из них, которыми, в свою очередь, определяется содержание.

Среди предметов основного общего образования передачу этнографических знаний предполагает содержание предметов: литература, история, обществознание и география. В частности, уроки литературы призваны способствовать культурной самоидентификации, изучение произведений своего народа и овладение навыками понимания разных этнокультурных традиций, воплощенных в художественных произведениях [8].

История обеспечивает формирование целостных представлений об историческом пути разных народов и государств, об условиях существования, основных занятиях, образе жизни и религиозных верованиях людей древности.

В отличие от истории, на уроках обществознания учащиеся приобретают знания о современности: явлениях духовной культуры, роли религии в обществе, ценностях российской культуры, а также навыки выявления причин межнациональных конфликтов и путей их разрешения.

Что касается географии, она призвана передавать комплекс знаний о современном населении стран и регионов: естественном и механическом движении, половозрастной структуре, трудовых ресурсах городском и сельском населении, этническом и религиозном составе, расовых отличиях. Таким образом, вышеперечисленные предметы содержательно поддерживают друг друга в процессе передачи этнографических знаний, однако наибольший их объем приходится на уроки географии [8]. Настоящая статья посвящена рассмотрению механизмов передачи этнографических знаний в процессе изучения школьной географии.

Цели, содержание и методы обучения географии тесно связаны между собой и находятся в определенном соподчинении [10, с. 20].

Согласно ФГОС, выделяется несколько типов школьных уроков по цели, каждый из которых определяется характером взаимодействия субъектов образователь- ной деятельности (педагога и учащихся) [9, с. 33-36]. Кроме того, нижеприведенные типы также связаны хронологически, образуя последовательность от получения учащимися новой информации до контроля ее усвоения.

На первом этапе проводится урок открытия нового знания, название которого четко описывает его основную направленность. В традиционной педагогике подобные уроки обычно сводятся к фронтальной устной передаче учителем необходимого объема новых данных и ее полной или частичной фиксации детьми в своих тетрадях. Однако такая организация работы не подходит для передачи этнографических знаний, связанных с эмоциональным восприятием. Достижения современного уровня развития техники и технологий в образовании открывают перед педагогами широкие возможности применения на уроках новых методов. Так, благодаря интерактивным технологиям открытие новых знаний может происходить в виде экскурсии, путешествия, экспедиции, конференции или игры. Такие приемы особенно уместны и эффективны на уроках географии при изучении культуры разных народов, природы районов их расселения.

После первого ознакомления наступает этап рефлексии, когда школьникам предлагается высказать свое отношение к поставленным проблемам. Обмен мнениями в системе ученик-ученик на уроке может проходить в форме деловой или ролевой игры, практикума, а результатом индивидуальной работы над информацией становится эссе или сочинение-рассуждение. Уроки рефлексии способствуют первичному закреплению материала, поддержанию мотивации детей к обучению, осознанию ими проблемности и важности обсуждаемых вопросов, что играет большую роль в процессе передачи этнографических знаний.

Уроки общеметодологической направленности призваны углубить и расширить понимание учащимися полученной информации, дополнить ее данными из новых источников, дать возможность детям применить на практике приобретенные умения и навыки. С учетом полиэтничности большинства классов, активное взаимодействие школьников между собой в рамках парной и групповой деятельности на уроке будет способствовать развитию у них этнокультурной компетентности через непосредственное общение с представителями других культур, совместное решение общих учебных задач. Для достижения вышеназванных целей такие уроки проводятся в форме конференции, конкурса, социальной игры, дискуссии, круглого стола, экскурсии и т.д. Важно отметить, что на этом этапе передача этнографических знаний может осуществляться не только и не столько от учителя к учащимся, сколько от каждого ребенка (группы детей) - одноклассникам, например, в процессе представления объектов материальной и духовной культуры 
своего народа, презентации национальных костюмов и блюд, рассказе об обычаях и традициях.

На последнем этапе проводится развивающий контроль усвоения полученных знаний, умений и навыков. Он может носить как традиционный - тестирования, письменные работы или устные опросы, так и творческий характер - конкурсы и викторины, защита проектов, презентация результатов исследования, рефераты. Как следует из названия, задачей этого типа урока является не только проверка, но и развитие навыков адекватной само- и взаимооценки учащихся, умения отвечать на поставленный вопрос, организовывать самостоятельную исследовательскую деятельность и представлять ее итоги перед аудиторией.

К сожалению, у педагога нет возможности отводить на каждую тему по четыре урока: для большинства из них в рабочей программе предусмотрено только одно занятие. Как следствие, перечисленные формы работы учащихся должны укладываться в эти рамки, что приводит к увеличению объемов «домашней» подготовки как детей, так и учителя. Однако такая ситуация развивает у школьников навыки самостоятельного поиска, отбора, анализа и систематизации информации.

Что касается содержательной части курса географии в 5-9-х классах, то Примерная основная образовательная программа предусматривает изучение населения, образа жизни и культуры регионов мира, анализ влияния исторических событий на современную этнокультурную ситуацию, подробное рассмотрение особенностей населения России, в том числе процессов воспроизводства и миграций, этнического и религиозного состава, расселения и урбанизации. Большое внимание уделяется и родному для учащихся региону, о географии которого они также получают всестороннюю информацию.

Программа воспитательной деятельности, реализуемая на уровне основного общего образования, направлена на воспитание компетентного гражданина России и основывается на национальных ценностях российского народа, таких, как патриотизм, семья, труд, здоровье, творчество и др. [8]. Процесс воспитания, согласно данной программе, должен обеспечить приобщение учащихся к культуре своей этнической группы, освоение ими духовно-нравственных ценностей российского народа и общечеловеческих ценностей. Следовательно, этнографические знания играют важную воспитательную роль, способствуя формированию не только этнической, но и общероссийской идентичности.

В шестом классе при изучении человеческих рас и народов мира дети получают первые представления этнологической направленности, в частности, о том, как природа влияет на рацион питания, тип жилища, занятия народов, проживающих в разных природных условиях [2, с. 60-63]. Данные темы обеспечивают передачу знаний о связи человека с природой территории его проживания: ее непосредственном влиянии на его внешний облик, питание, предметы быта и способы хозяйствования.

Курс географии седьмого класса традиционно посвящен материкам и океанам Земли. В течение года учащиеся знакомятся с особенностями природы: строением земной коры, рельефом, климатом, внутренними водами и природными зонами, а также населением и несколькими наиболее крупными странами каждого из материков [3, с. 12-15]. Благодаря своему содержанию, данный курс выступает одним из наиболее благоприятных для передачи этнографических знаний. В этой связи одной из задач на уроках географии в седьмом классе должно стать раскрытие, с одной стороны, неразрывной связи между природной средой и культурой народов, традиционно в ней проживающих, а с другой - влияния на культуру религиозного мировоззрения и особенностей исторического развития. Такой подход обеспечит межпредметную связь, повысит проблемность рассматриваемой темы и позволит школьникам глубже понять причины, лежащие в основе материальной и духовной этнокультурной специфики отдельного народа.

Согласно Примерной основной образовательной программе курсы географии восьмого и девятого классов отводятся для изучения России и, как следствие, направлены на расширение знаний детей о местности их проживания, населяющих ее народах, об их культуре, в том числе о своей собственной [4, с. 40-53]. Проживание в условиях исторически сложившейся этнической ситуации, полиэтничность классов и ежедневная совместная деятельность школьников с представителями разных народов позволяют на практике получать этнографические знания и формировать этнокультурную компетентность на их основе.

Основное содержание географического образования отражено в учебниках, одобренных Министерством просвещения РФ и входящих в Федеральный перечень учебников. В начале 2019 г. в него входили учебники географии линий «Полярная звезда» издательства «Просвещение» и линия «Климановой-Алексеева» издательства «ДРОФА» [12]. Каждая линия состоит из серии учебников для 5-9-х и 10-11-х классов, объединенных схожей структурой, оформлением, аппаратами ориентировки и контроля усвоения. Преемственность между ними обеспечивает единство образовательного процесса.

В зависимости от типа урока географии и педагогических приемов, используемых учителем, учебник может играть роль основного источника информации, частичной поддержки или вообще не использоваться. При 
методически правильном подходе учебник может стать самодостаточным инструментом передачи этнографических знаний. Активное использование учебника актуально на уроках открытия нового знания, развивающего контроля. Многие современные учебники географии также предлагают учащимся широкий выбор тем для проектных и исследовательских работ.

Педагогические методы, используемые для передачи этнографических знаний, напрямую зависят от содержания конкретной темы.

Метод наглядности, широко применяемый в преподавании различных школьных предметов, играет важнейшую роль в обучении географии на любом уровне. В части передачи этнографических знаний использование этого метода позволяет дать представление о таких важных элементах культуры, как национальный костюм, традиционные блюда, игры, праздники, фольклорные герои, музыкальные инструменты, предметы быта и ритуала и т.д. Наглядность также может использоваться на стадии рефлексии учащихся, когда им предлагается в символах представить изученный народ, страну, группу стран, материк и т.п. Такое задание направлено не только на первичную проверку усвоенного материала, но и на развитие творческого потенциала и формирование собственного, уникального для каждого ребенка, взгляда на изучаемый объект [6, с. 271]. В рамках учебника применение метода наглядности предполагает активное вовлечение внетекстового компонента его структуры: иллюстраций, аппарата организации усвоения. Современные информационные технологии позволяют педагогу демонстрировать наглядные материалы на любом этапе урока, что способствует облегчению процесса управления пониманием рассматриваемой проблемы, активизации внимания и мотивации учащихся [11, с. 106], а также поддержанию общего интереса к изучаемой теме.

Сравнительный метод в контексте этнокультурной составляющей обучения географии приобретает форму кросс-культурного, главная задача которого - показать учащимся общие и отличительные черты разных культур через их сравнение между собой. В учебнике это может быть осуществлено как в рамках текста (основного или дополнительного), так и в блоке заданий. Аналитическая и синтетическая деятельность в процессе сравнения позволяют детям обратить внимание на значимые особенности, что приближает их к пониманию данных культур, а также осознать существование общих черт, позволяющих многим народам мирно сосуществовать и взаимодействовать. К достоинствам данного метода можно отнести возможность его применения на любом уровне обучения географии. На начальном этапе сравнительный метод требует от педагога проведения значительной организационной работы с учащимися в виде формулирования цели и подготовки плана сравнения, подбора критериев, представления выводов [7, с. 138]. Однако в дальнейшем, после овладения школьниками соответствующими навыками, внимание будет концентрироваться непосредственно на результатах. Большую роль в применении данного метода играет не зависящая от содержания учебных изданий установка учителя на передачу этнографических знаний и, как следствие, формирование у детей этнокультурной компетентности.

Главным методическим приемом, используемом на уроках географии и способствующем накоплению учащимися этнографических знаний, выступает учебная задача, представляющая собой обобщенное учебное задание, в процессе решения которого у детей формируются знания, умения и личностные качества как результат достижения цели учебной деятельности [5, с. 230].

В зависимости от задействованных в процессе обучения мыслительных операций весь массив учебных задач принято делить на пять групп. К первому типу относятся задания, требующие простого воспроизведения полученной информации. Они хорошо подходят для первичного закрепления материала или актуализации ранее полученных знаний. Для решения задач второго типа необходима систематизация фактов или описание объектов и явлений. Такие вопросы хорошо сочетаются с кросс-культурным методом и помогают учащимся вычленять существенные признаки, классифицировать и обобщать. Третью группу составляют задачи на сложные операции - объяснение и аргументацию. Дети учатся искать зависимости между фактами, доказывать свою точку зрения. Наибольшей сложностью отличаются задания последних двух групп, требующих продуктивной и креативной мыслительной деятельности, результатом которых должно стать полное развертывание цепочки причинно-следственных связей, творческое решение конкретной проблемы с применением знаний в новой ситуации.

В силу предметных особенностей причинно-следственные связи являются основой географии. Таким образом, решение учебных задач четвертого и пятого типов играют важную роль в понимании учащимися взаимосвязей в системе природа-человек-хозяйство (культура), выступающей объектом исследования географической науки. Однако это не означает, что другие типы задач нужно опускать. В ходе урока педагог обеспечивает и контролирует последовательное решение заданий всех групп, в результате которого у учащихся создается ситуация успеха и происходит наиболее полное усвоение знаний, формирование умений, навыков и компетенций. В процессе передачи этнографических знаний одной из основных задач учителя географии является раскрытие причинно-следственных связей между природой и культурными особенностями населения на кон- 
кретной территории.

Этнографические знания как комплекс представлений личности об особенностях культуры своего и других народов: истории происхождения, материальных и духовных ценностях, обычаях и традициях, хозяйственной деятельности - играют важную роль в становлении этнической идентичности и осознании многообразия современного полиэтнического общества. На этом фундаменте впоследствии строится умение человека вести мирный диалог и организовывать эффективное взаимо- действие с представителями разных культур - этнокультурная компетентность. Основную, фактическую часть этнокультурных знаний ребенок получает во время обучения в школе на уроках географии при поддержке истории, литературы и обществознания. Сложившаяся современная система целей, содержания и методов географического школьного образования обеспечивает реализацию механизмов передачи этнографических знаний не только от педагога к учащимся, но и между учащимися в процессе совместной учебной деятельности.

\section{ЛИТЕРАТУРА}

1. Азимов Э.Г., Щукин А.Н. Новый словарь методических терминов и понятий (теория и практика обучения языкам). М.: Издательство ИКАР, 2009.448 с.

2. География. 5-6 классы: учеб. для общеобразоват. организаций / А.И. Алексеев, В.В. Николина, Е.К. Липкина и др. М.: Просвещение, 2018. 191 с.

3. География. 7 класс: учеб. для общеобразоват. организаций / А.И. Алексеев, В.В. Николина, Е.К. Липкина и др. М.: Просвещение, 2018. 256 с.

4. География. 8 класс: учеб. для общеобразоват. организаций / А.И. Алексеев, В.В. Николина, Е.К. Липкина и др. М.: Просвещение, 2018. 256 с.

5. Лобжанидзе А.А. Этнокультурная парадигма школьного географического образования как средство реализации культурологического подхода: дис. ... докт. пед. наук. М., 2009. 353 с.

6. Поштарева Т.В. Формирование этнокультурной компетентности учащихся в полиэтнической образовательной среде: дис. ... докт. пед. наук. Ставрополь, 2007. $385 \mathrm{C}$.

7. Приемы работы с текстами в социально-гуманитарных дисциплинах (обществознание, история, география) / Е.А. Крючкова, Э.М. Амбарцумова, И.А. Лобанов и др. // Наука и школа. 2018. №4. URL: https://cyberleninka.ru/article/n/priemy-raboty-s-tekstami-v-sotsialno-gumanitarnyh-distsiplinahobschestvoznanie-istoriya-geografiya (дата обращения: 14.02.2020).

8. Примерная основная образовательная программа основного общего образования: одобрена федеральным учебно-методическим объединением по общему образованию 8 апреля 2015 г. URL: https://fgosreestr.ru/registry/по0п_000_06-02-2020/ (дата обращения 01.02.2020).

9. Современный урок в условиях реализации Федерального образовательного стандарта среднего профессионального образования: учебно-методическое пособие. Челябинск: ЗАО «Библиотека А. Миллера», 2018.59 с.

10. Таможняя Е.А. Методика обучения географии: учебник и практикум для академического бакалавриата / Е.А. Таможняя, М.С. Смирнова, И.В. Душина; под общ. ред. Е.А. Таможней. М.: Юрайт, 2018. 321 с.

11. Усольцев А.П., Шамало Т.Н. Наглядность и ее функции в обучении // Педагогическое образование в России. 2016. №6. URL: https://cyberleninka.ru/ article/n/naglyadnost-i-ee-funktsii-v-obuchenii (дата обращения: 14.02.2020).

12. Федеральный перечень учебников. URL: http://www.fpu.edu.ru (дата обращения 15.09.2019).

(c) Петрухина Дарья Валерьевна (darkamercante@gmail.com). 